\title{
Some techniques and methods of soil survey in the Netherlands
}

\author{
P. BURINGH, G. G. L. STEUR and A. P. A. VINK
}

Reclamation and Land Development Society, Arnhem; Soil Survey Institute, Bennekom; and International Training Centre for Aerial Survey, Delft, respectively. The Netherlands

\section{Introduction}

In the past little has been published on methods and techniques of soil survey in the Netherlands, although a large number of soil maps and reports of various parts of the country have been published by the Soil Survey Institute at Wageningen.

The increasing utilization of soil maps for various purposes and the systematic reconnaissance soil survey of the whole country which started recently, have created more interest in these subjects. Various members of the Dutch Soil Survey Staff have contributed to the development of the methods (see literature at the end of this article).

A number of subjects, dealing with the methods of soil survey will be discussed here. The techniques referring to the soil surveys in newly reclaimed land (ZuUR, 1951; SMITS and WIGGERS, 1959) will not be considered, because those investigations have specific problems, due to the special soil conditions in those areas.

\section{Soil survey and soil units}

Soil survey refers to the study, classification, mapping and description of the soil conditions in an area. Work is manily based on the study of the terrain and the soil profiles. The profiles are investigated in pits to a depth of 1 to $2 \mathrm{~m}$. Comparing the soil profiles some are almost similar, others show differences in various characteristics. Soils therefore can be classified in various units. The classification is based on the differences in characteristics which are the result of variations in soil forming processes. Such a classification is called a taxonomic soil classification.

After setting up a soil classification, soils with almost similar characteristics can be grouped in units and their delineation can be determined with the aid of many field observations. The result is a soil map and report, showing and explaining the results of the investigation.

The smallest three dimensional unit of the earth's surface which can be called "a soil", is given the name pedon (Greek for soil). Its lower limit normally is the somewhat vague transition between the soil and the underlaying unweathered parent material or the lower boundary of rooting of native perennial plants. The total area covered by a pedon (often 1 to 10 sq. $\mathrm{m}$ ) should have a sufficient extent to include some profile deviations of small dimensions. In investigating soil profile pits proper pedons are studied.

In the taxonomic soil classification pedons with minor differences in soil charac-

Received for publication 29th January, 1962.

Neth. J. agric. Sci., Vol. 10 (1962) No. 2 (May) 
teristics are combined in a soil series. A number of soil series, having common specific characteristics are grouped in a higher unit of classification, a soil family. Some families can be combined to form a subgroup.

At higher levels of classification a distinction is made in groups, suborders and orders. The Netherlands system of soil classification consists of 5 soil orders (ScHELlING, 1959; STEUR, 1959), the U.S.-system, which is intended for a world-wide use, has 10 orders (Soil Survey Staff, 1960).

The soil classification units just mentioned seldom are identical with units on soil maps, which often are indicated by the same name. In mapping soils in the field the geographical distribution and the relation between the various soil units is shown. In practical soil mapping it often is necessary to include a certain percentage of deviating taxonomic soil units in the soil mapping units (see paragraph 8).

Those soil mapping units are indicated on soil maps with colors and symbols, on the legend they are indicated with a name and in the report a detailed description is given.

An intricate pattern of soils occurring in the terrain sometimes prevents the representation on a map of a certain scale Various soil mapping units then have to be combined in a more complex soil mapping unit, called soil association.

It is evident that besides a soil classification system, which gives a classification of pedons, a special system for the classification of soil mapping units with specific principles has to be developed. Such a system is called a soil mapping-unit classification. Reference is made to a similar procedure followed in botany. The taxonomic soil classification is identical with plant systematics and the cartographic soil classification with plant geography.

\section{Characteristics, properties and qualities of soil units as related to the choise of mapping criteria}

Each cartographic soil unit or soil mapping unit is characterized by its position in the terrain, its size, form of the surface and soil profile. It has specific physical, chemical and biological properties and in addition also some qualities, which are not only determined by the soil itself, but also by external influences. Therefore, a distinction is made between soil characteristics, properties and qualities.

Besides the characteristics just mentioned (position, size and form), those of the soil profile have to be included, e.g. various horizons and layers, ground-water level and its fluctuations, parent material, etc. and of every horizon and layer also: thickness, boundary, depth, color, texture, structure, consistency, organic matter, lime, pores, chemical and mineral composition, density, pore space, etc.

Important physical, chemical or biological properties of a soil unit are: moisture and air conditions, vertical and horizontal permeability, root density and depth, biological activity, fertility, etc.

Soil qualities are for example : suitability for specific crops or crop-rotation systems, potentialities, drainage requirements, use possibilities, tillage, etc. For the determination of the soil qualities other, non-soil factors have to be considered too, e.g. economic, geographic, social, climatic or historic factors. Such soil qualities are interpretations of soil properties, which are made for specific, well defined circumstances. The fundament of soil mapping in the field is the study of clearly perceptible and measurable soil characteristics in profiles (morphometric characteristics), on which the classification is based. The result can be reproduced and consequently soil units can 
be differentiated and compared. It is necessary to follow certain rules and to agree on mapping criteria which, therefore, have to be mentioned in the report. However, the final purpose is not a description of soil profiles and their characteristics, but an interpretation of characteristics and properties in order to be informed on soil qualities. This often is rather difficult. Chemical properties mostly have to be determined in a laboratory. A number of physical properties can be studied in the field. Some can be deduced from a combination of certain characteristics. This also holds for biological properties. Soil qualities, however, are determined as a result of an evaluation including some external factors.

In mapping soils the criteria are selected in such a way that the classification is based on the more permanent soil properties. Those properties which vary during the seasons (fertility, ground-water level, moisture content, etc.) cannot be used in classifying soils. It is also impossible to make distinctions merely based on properties determined in a laboratory, because every surveyor would daily collect some hundreds of soil samples, too much for the capacity of any laboratory. In most soil surveys one or more typical soil profiles, characterizing the soil units mapped, are sampled and analysed in detail. In this way a large amount of information on every soil mapping unit is collected. It is supposed that other sections of the terrain, having similar internal and external profile characteristics as those which have been investigated in detail, can be considered as being equal. Therefore, they are indicated on the soil map with the same soil mapping unit. Several soil properties can be correlated with specific morphometric characteristics resulting in a reliable map. Some important soil properties can be correlated with external characteristics of a soil unit (e.g. position in the terrain, relief, etc.). In such circumstances soil boundaries can be easily plotted and with great accuracy. Some methods of aerial photo interpretation in soil survey are based on this principle (BURINGH, 1960).

It is evident that a soil survey always has to start with an intensive investigation of terrain conditions and soil profiles over the whole area, to determine :

1. the characteristics on which the mapping has to be based;

2. the variations of these characteristics and how to group them in classes;

3. in which way they have to be correlated with important soil properties;

4. the soil properties of the mapping units ;

5. how the soil qualities are influenced by the properties observed.

These five points have to be worked out consecutively. Without a sound investigation and knowledge no decision can be made on the soil qualities.

\section{Characteristics of soil surveys}

There are often two groups of soil scientists, both following different principles in trying to evaluate the qualities of soils. One group, following principles of analytical pedology works on some profiles only. With the help of soil samples investigated in the laboratory many soil properties are analysed. If possible the evalution of the soil is checked by field trials.

The other group, mainly following methods of field investigation works on a systematic study of soils in the field in combination with observations on crops, farm systems, etc. Typical soil samples are analysed in the laboratory; however, the work mainly concentrates on mapping variations in soil conditions, which leads to an evaluation of soil qualities in a regional pattern. 
The scientists of the first group are well informed on some specific points, whereas those of the second group know less about each observation, however, the latter know more on the most important facts and the possibility of application of the results obtained. It should be kept in mind that not all soil surveys, and in particular not all of the older ones, are based on intensive investigations. Soil survey is still a young section of soil science which is in a rapid development. A systematic regional investigation of soils is not only a routine work resulting in an inventory. Methods and techniques of regional comparison and correlation have given a specific position to soil survey among other branches of pedology.

\section{Soil units and field observations}

A soil unit, being a three dimensional section of the earth's surface, has many characteristics that often are mutually associated. The classification and mapping, therefore, is not based on one single soil characteristic (except when somebody wants a single-value map) but on a group of soil characteristics which determine important soil properties. Often it is not necessary and even impracticable to map very small and unimportant differences among soils. Therefore, there is no reason to classify specific soil characteristics or properties in many classes.

Soil mapping units indicate typical differences in specific combinations of soil characteristics and properties. A system of mapping-unit classification has to be developed. The units and their boundaries have to be plotted. A large number of observations on profile pits or borings have to be executed. In an area with only slight differences in soil characteristics less observations per surface unit have to be carried out than in areas with great differences in soil characteristics. A large number of observations per surface unit also have to be made if many mapping units for a certain group of soil characteristic have been set up. Consequently the criteria on which a cartographic classification is based influence the intensity of field observations. On the other hand, soil conditions too affect the number of observations. In an area with an intricate soil pattern a great number of field observations is needed, but the same number of units leads to a much smaller number of field observations in an area with less complicated soil conditions.

The number of observations per surface unit largely determines the quantity of field work and, therefore, the cost and duration of the investigations. Time, man-power and funds have often to be taken into account as limiting factors in setting up a scheme of mapping units in soil survey.

As soon as a preliminary study of soils in the field has resulted in a list of soil mapping units and their characteristics, field observations are made and the soils can be mapped.

Three types of field observations can be distinguished, viz.

a. classification observations,

b. plotting observations,

c. special observations.

Classification observations are made in order to determine which soil mapping unit occurs on the spot where the observation is made. Very soon the surveyor knows where the various mapping units occur; the location of the boundaries between the units, however, is not exactly known. Therefore, it is necessary to increase the number 
of observations to enable an accurate plotting of the soil boundaries on the map. Such observations are called plotting observations. If external characteristics (relief, differences in vegetation, etc.) correlate with the location of the boundaries, the latter can easily be plotted and the number of field observations (plotting observations) can be decreased. The classification observations always have to be made.

In a soil survey of an area where almost no terrain characteristics indicate the location of soil boundaries approximately $25 \%$ of the total number of field observations serve the classification, whereas approximately $75 \%$ serve the plotting of soil boundaries.

If soil mapping units correlate with terrain characteristics the number of plotting observations can be reduced. Another decrease in the number of plotting observations can be obtained by applying proper methods of systematic aerial-photo interpretation.

Special observations are made in order to investigate special phenomena, to collect additional data, to sample and describe typical soil profiles, to measure the permeability, to investigate the deeper underground, etc. Such special observations mostly are made on spots where already classification observations have been made and which are typical for the soil units concerned.

The total number of field observations per surface unit increases if the soil pattern becomes more complicated and if the course of the boundaries becomes more capricious. This mainly results in an increase of the number of plotting observations. A very high accuracy of the location of the soil boundaries also increases the number of these observations.

A soil map can be detailed as far as soils are concerned but it also can be detailed from a point of view of cartography. Examples are given in FIG. 1 and 2. The soil map in FIG. 1 is quite a detailed map, because there is a detailed classification of soils based on slight variations in soil conditions. In FIG. 2 the map shows a large amount of cartographic detail. There is no detailed classification of soils but still the soil boundaries are plotted quite in detail. A comparison of both maps shows that the differences in soils among the various mapping units are small in FIG. 1, whereas in FIG. 2 these differences are much larger but, on the other hand, the pattern of the soil units is much more complicated.

The result of a soil survey of the area shown in FIG. 1 with the soil legend of FIG. 2 is indicated in FIG. 3. The soil map of FIG. 2 is rather unbalanced. It suggests details in soil characteristics but in fact it only shows cartographic details of an intricate pattern of soils with large differences in soil characteristics.

Soil surveyors strive after a deliberate balance between the representation of soil data on a map and the average number of field observations per surface unit. Generally the production of maps like that in FIG. 2 has to be avoided.

\section{The scale of the soil map and the basic mapping unit}

Maps or aerial photographs are used in the field for plotting points of observation, soil boundaries, symbols, etc. In general the scale of these field maps is such that the distance between two points of observation on the map is approximately $1 \mathrm{~cm}$. On such a map plotting can be carried out carefully and accurately.

The final soil map which is drawn from the field map and often is printed always has a much smaller scale. An important aspect is the legibility of the final soil map. In this respect it is a condition that the map must be legible at a distance 
FIG. 1. Detailed soil map showing slight differences in soil conditions. The legend is based on a detailed classification

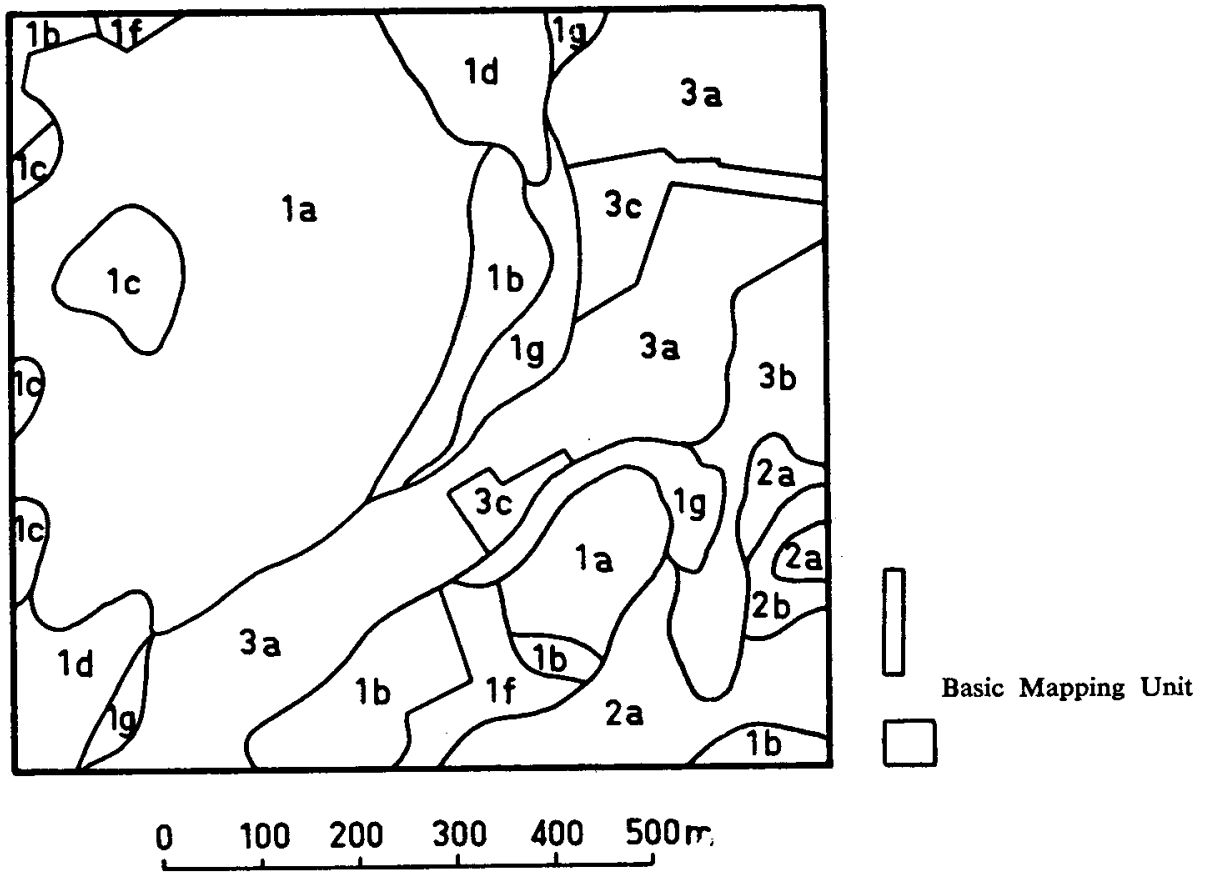

\section{Legend}

1. Soils with a thick humose topsoil $\left(\mathrm{A}_{\mathrm{an}}\right)$

1a. Topsoil $>80 \mathrm{~cm}$ humose, loamy fine sand, overlying yellowish, slightly loamy fine sand.

1b. Topsoil as 1a, overlying rusty, loamy fine sand.

1c. Topsoil $50-80 \mathrm{~cm}$ humose, loamy fine sand, overlying yellowish, slightly loamy fine sand.

1d. Topsoil as $1 \mathrm{c}$, overlying rusty, loamy fine sand.

1f. Topsoil as $1 \mathrm{c}$, overlying slightly loamy podzol-B.

1g. Topsoil as 1c, overlying whitish loam.

2. Humuspodzol soils

2a. Topsoil $30-50 \mathrm{~cm}$ humose, slightly loamy fine sand, overlying slightly loamy, fine sandy humuspodzol.

2b. Topsoil $30-50 \mathrm{~cm}$ humose, loamy fine sand, overlying slightly loamy, fine sandy humuspodzol.

3. Gley soils

3a. Topsoil $30-50 \mathrm{~cm}$ humose, loamy fine sand.

3b. Topsoil $<30 \mathrm{~cm}$ humose, loamy fine sand.

3c. As 3b, but heterogenous.

of approximately $30 \mathrm{~cm}$. The smallest area of a soil unit on a map and the symbols printed in this unit should be clearly visible. Similar conditions are set for type and size of characters in a book or magazine. Considering these conditions, it is found that the smallest area which can be indicated on the final soil map (basic mapping unit $)$ is approximately $1 / 4$ sq. $\mathrm{cm}(5 \times 5 \mathrm{~mm})$, see FIG. 1,3 and 5 . If the basic mapping unit would be smaller a symbol hardly could be printed within such an 
FIG. 2. Soil map showing much cartographic detail. The legend is intended to map the main differences in soil conditions

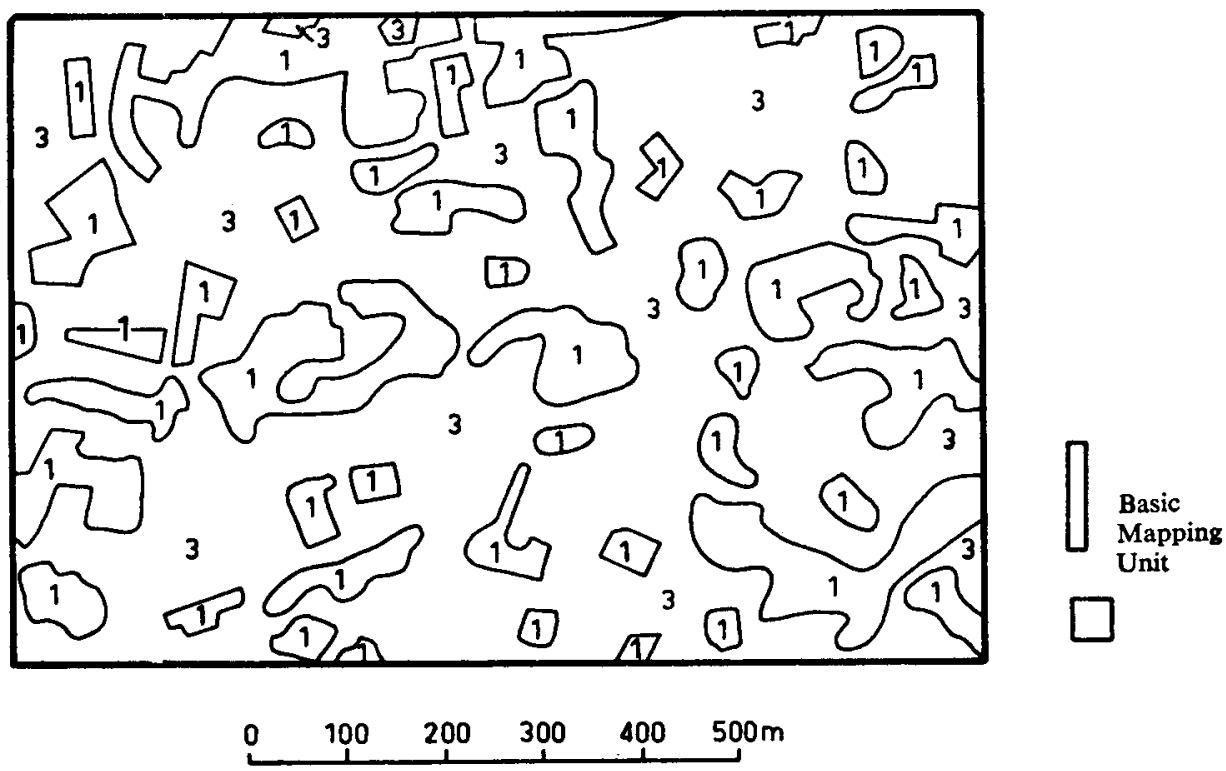

\section{Legend}

1. Soils with a thick humose topsoil (Old arable land).

3. Gley soils.

area and it also would be difficult to read and study the soil map. For soil mapping units with a narrow elongated form the minimum distance between the almost parallel boundaries on the final soil map is approximately 2 to $3 \mathrm{~mm}$.

In plotting soil boundaries on a map with sufficient accuracy approximately 9 field observations have to be made in an area represented by $1 \mathrm{sq} . \mathrm{cm}$ on the final soil map, if the location of the boundaries is only determined by borings. The distance between the points of observation on the map is then approximately $3 \mathrm{~mm}$. Soil boundaries have to be plotted on the map between those points. The lines indicating the soil boundaries on the map often are $0,3 \mathrm{~mm}$ wide. In all directions there is a space of approximately $1 \mathrm{~mm}$, which is almost equal to the accuracy of drawing a map and of the technical possibilities of map reproduction and printing. If the number of observations per area represented by $1 \mathrm{sq} . \mathrm{cm}$ of the map is increased (e.g. to 15 or 20 observations) the accuracy of the position of the soil boundaries on the map would not increase, considering the technical limitations. Consequently, for the final soil map the following three requirements have to be met:

1. The number of field observations per area representing $1 \mathrm{sq} . \mathrm{cm}$ of the final map is approximately 4 to 9 . This number can be smaller if proper methods of aerial photo interpretation are applied.

2. The area of the basic mapping unit on the final soil map is $1 / 4 \mathrm{sq} . \mathrm{cm}$.

3. For elongated mapping units the smallest distance between two almost parallel soil boundaries is $2 \mathrm{~mm}$ on the final soil map. 
Frg. 3. The soil map of FIG. 1 showing only differences in soil conditions as indicated in FIG. 2

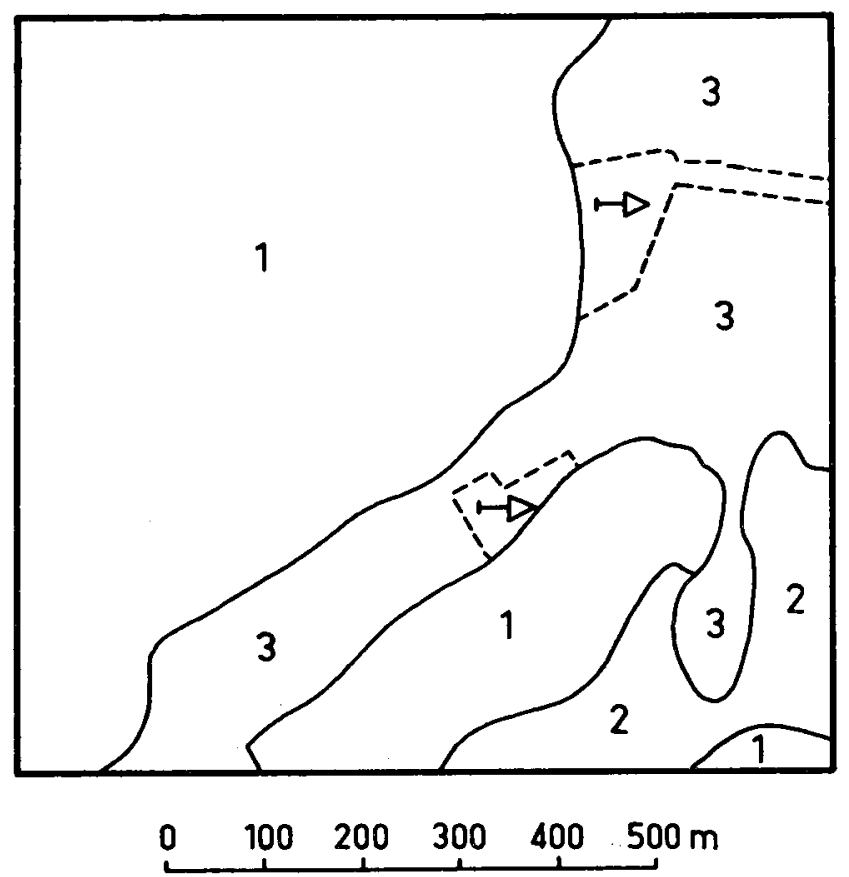

\section{Legend}

1. Soils with a thick humose topsoil (Old arable land).

2. Humuspodzol soils.

3. Gley soils.

$1 \rightarrow$ Heterogenous.

This means on the one hand, that the scale of the final soil map has to be larger if the distance between the points of observation in the field becomes shorter. On the other hand, the density of the field observations per surface unit has to be in harmony with the scale of the final soil map.

It is rather difficult to maintain this rule if the pattern of soil mapping units in the field is complicated. Consequently, the number of observations could be increased. A legend of soil mapping units which is too detailed for a specific type of soil survey, may lead to an increasing number of observations (see FIG. 1, 2 and 3). Therefore, it is important to find a balance between the soil pattern on the one hand, and the legend and number of observations on the other hand.

Taking into account the various conditions mentioned before, the accuracy of the soil boundaries on a soil map is the same for all kinds of mapping scales. Only on small scale maps the exact delineation of the soil boundaries may deviate as a result of the generalization which has to be made on these maps (FIG. 4).

Many soil maps, all over the world, are printed on too large a scale; they often do not meet the requirements of scale, accuracy, and representation of soils as mentioned before. Enlarging a soil map does not imply more accuracy or more 
Fig. 4. Differences in delineation of the same soil boundary on soil maps of various scales as a result of generalization

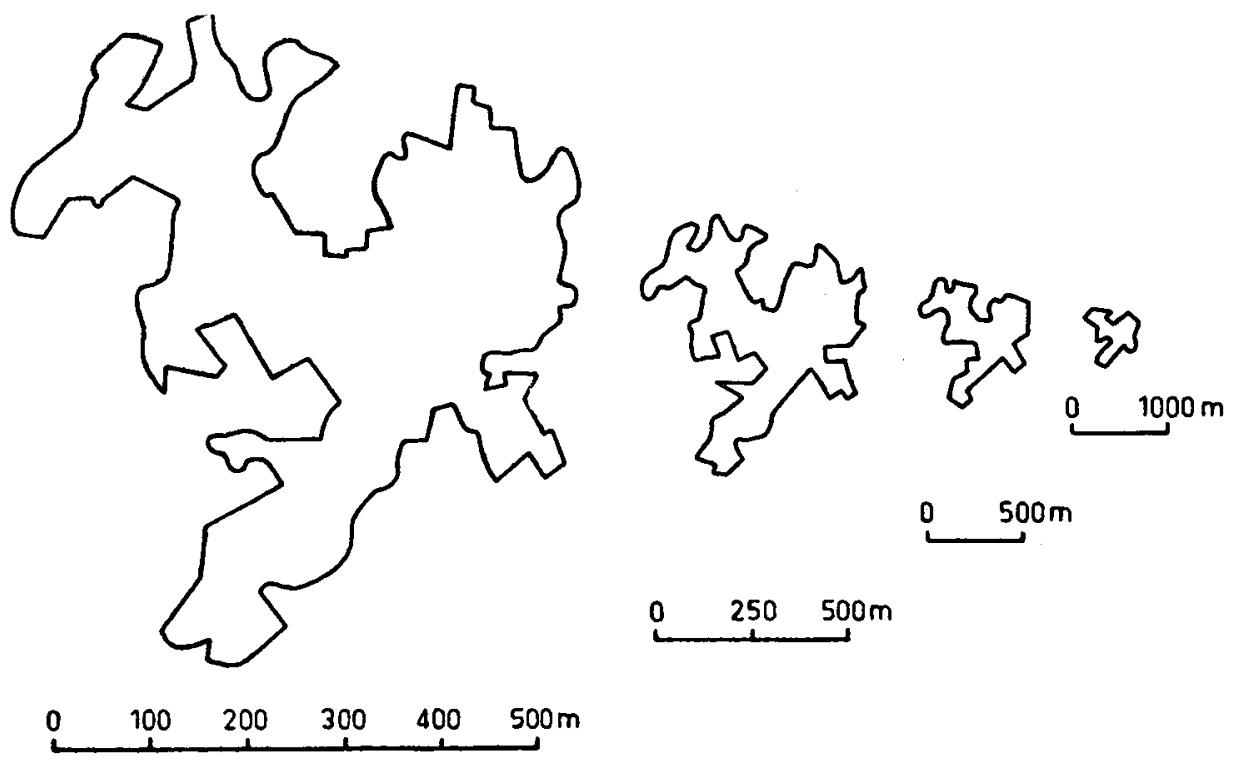

details in the representation of soil units. If a quantitative indication of the accuracy of the map is given the printing scale of the final soil map is not important at all. Therefore, the name of the map need not refer to its scale. It is therefore proposed to indicate on each soil map a small square and an elongated rectangle representing the basic mapping unit in a similar way as is indicated in FIG. 1,2 and 5 . If this system is generally adopted a quantitative comparison of the accuracy of soil maps becomes possible and a lot of confusion will be avoided.

If for a certain area and for a particular purpose the minimum area of the basic soil unit is fixed, consequently the mapping scale of the soil survey is largely determined. From this the number of field observations per surface unit can be calculated too. At least 1 or 2 field observations have to be made in each area equal to the basic mapping unit, except when a proper systematic analysis of aerial photographs can be applied.

In those sections of the project area where soils are rather uniform, the same density of field observations has to be maintained, because a small section of the size equal to or somewhat larger than that of the basic mapping unit has to be indicated on the soil map if its soil has to be classified in a different soil unit.

\section{Application of aerial photographs}

The above mentioned rules hold for the conventional methods of soil survey based on field work. A few times it is indicated that the number of observations, in particular of the plotting observations, can be reduced by applying methods of systematic aerial photo interpretation (BURINGH, 1960). This does not influence the quality of the soil map, on the contrary, most soil maps prepared in this way are even more accurate than those made according to the conventional methods. There 
Frg. 5. Example of an unbalanced special soil map, scale $1: 3.000$

A. Basic Mapping Unit belonging to the central part intended for a tile-drainage plan.

B. Basic Mapping Unit belonging to the rest of the map, a detailed soil map.

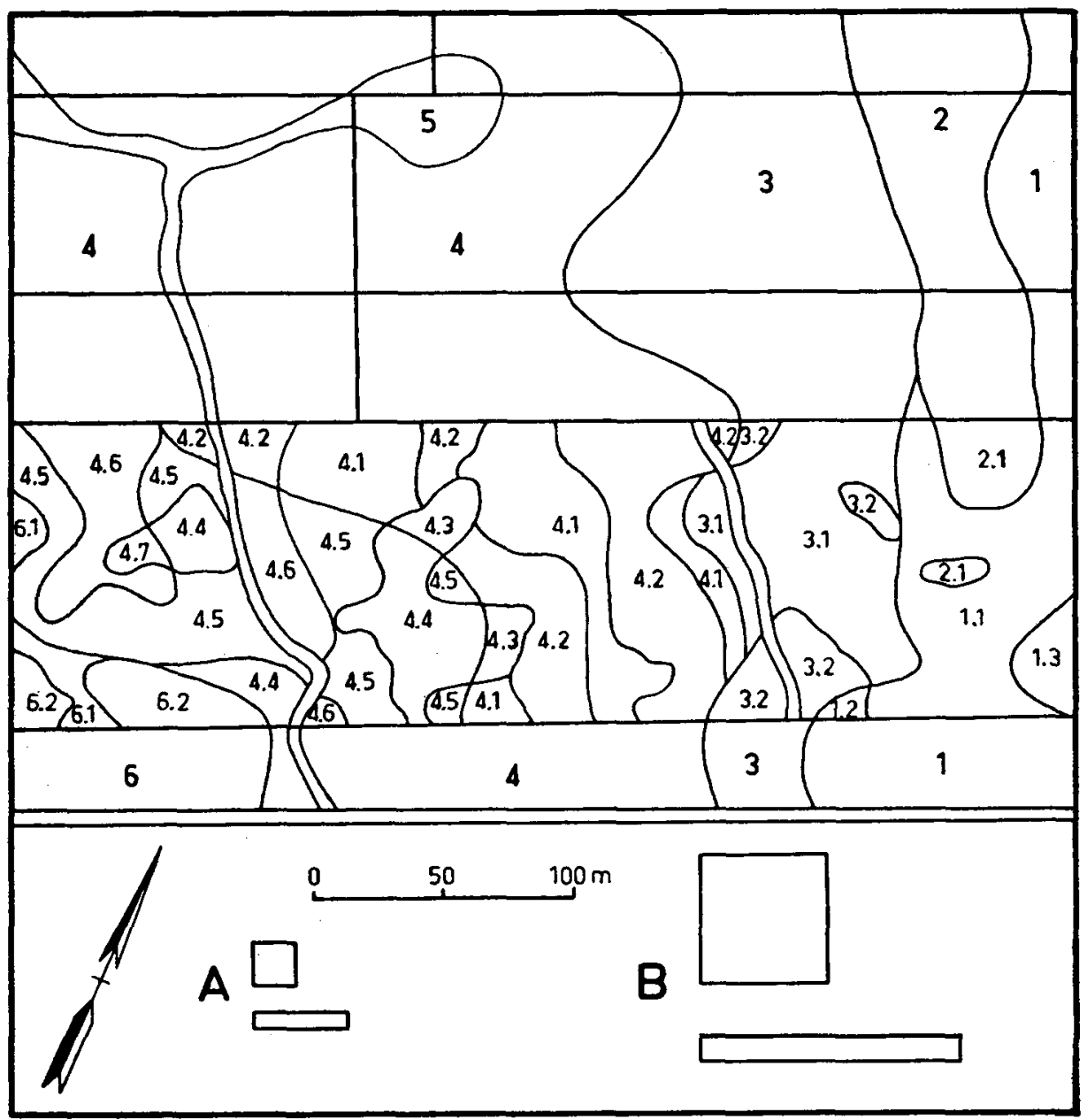

are, however, some consequences as to the way in which the cartographic classification of soils is applied.

The result of aerial photo interpretation in a soil survey mainly depends on :

a. the experience of the soil surveyor in mapping soils in the field and in aerial photo interpretation,

b. the quality of the photographs,

c. the nature of the terrain,

d. the purpose, type and scale of the soil map to be made.

All these factors also influence the problems under consideration. The quintessence of the considerations, however, is not affected. 


\section{Pedological and cartographic uniformity of soil maps}

The representation of soils on a map should be uniform all over the mapped area, otherwise the soils in the various sections of the terrain cannot be compared.

For the uniformity of the map the purity of the soil mapping units has to be agreed on. This purity refers to the percentage of the surface of a particular mapping unit on the soil map which really consists of soils as described in the legend and the report.

Practical field survey learns that in each mapping unit small inclusions with a deviating soil profile do occur. The area of those inclusions always is smaller than the area of the basic mapping unit otherwise it should be mapped separately. In the Soil Survey Manual Soil Survey Staff, 1951) it is indicated that at least $85 \%$ of each unit on the soil map must be in concordance with the description concerned. In the Netherlands this percentage often is set at $70 \%$, because many soils show deviations at short distances. In practice it often occurs that within a particular soil unit many small parts are characterized by different soils. If the total area of such parts is more than $30 \%$ of the soil unit, it will be necessary to indicate such an area as a soil complex. This has to be indicated in the legend too, whereas a description of such a complex should be given in the report. Little attention has been given to this problem in most soil surveys. Therefore, it should be tried to set up some specific rules for the purity of mapping units on soil maps.

From a cartographic point of view a soil map should be uniform too. If in certain sections of the project area soil units are mapped, they also have to be indicated for other sections if they do occur there as well. If this is not done, the map would be unbalanced.

Sometimes soil maps are made for particular purposes and less attention is paid to the cartographic uniformity. An example is given in FIG. 5, showing a soil map with many details in one part and less details in others. This is done, because those details were needed for a tile-drainage plan. In the area mapped in less detail no tile drainage was to be carried out as a result of a different type of land use. In such a case it is important to indicate the difference in cartographic uniformity on the soil map and in the report.

The soil surveyor has to follow certain rules when making a soil map. However, sometimes important details would not be indicated on the map, because these details

a. only occur locally,

b. occupy too smal an area, or

c. only occur at some points of observation and in an irregular pattern.

In such cases special symbols can be drawn on the map in order to indicate the exact location of the points at which those features have been observed. This system is to be preferred to the method of drawing a circular line (not indicating a soil boundary !) around the point of observation. Soil maps having many soil units are often unreliable soil maps.

\section{Plotting soil boundaries}

Soil profile pits and auger holes are made in order to determine the kind of soil unit and the boundaries of the soil. An experienced soil surveyor needs less observations than an unexperienced man, particularly if soil boundaries are clearly indi- 
cated by terrain characteristics (e.g. relief and differences in development of the vegetation).

Soil surveys which have to be carried out in detail, can only be made by observations regularly distributed over the whole area. Such details generally do not correlate with terrain characteristics. Therefore, field observations mostly are made on regular distances in a grid-system. If the soil boundaries are almost parallel to each other, a rectangular system with the largest distances parallel to the soil boundaries is followed (FIG. 6).

Important differences in soil conditions often correlate with terrain characteristics. For the surveyor it is then quite easy to plot boundaries with a high accuracy, whereas relative less observations are needed. He may carefully determine in the

FIG. 6. Part of a field map; grid survey. Baselines perpendicular to the main differences in soil conditions. After STEUR (1961)

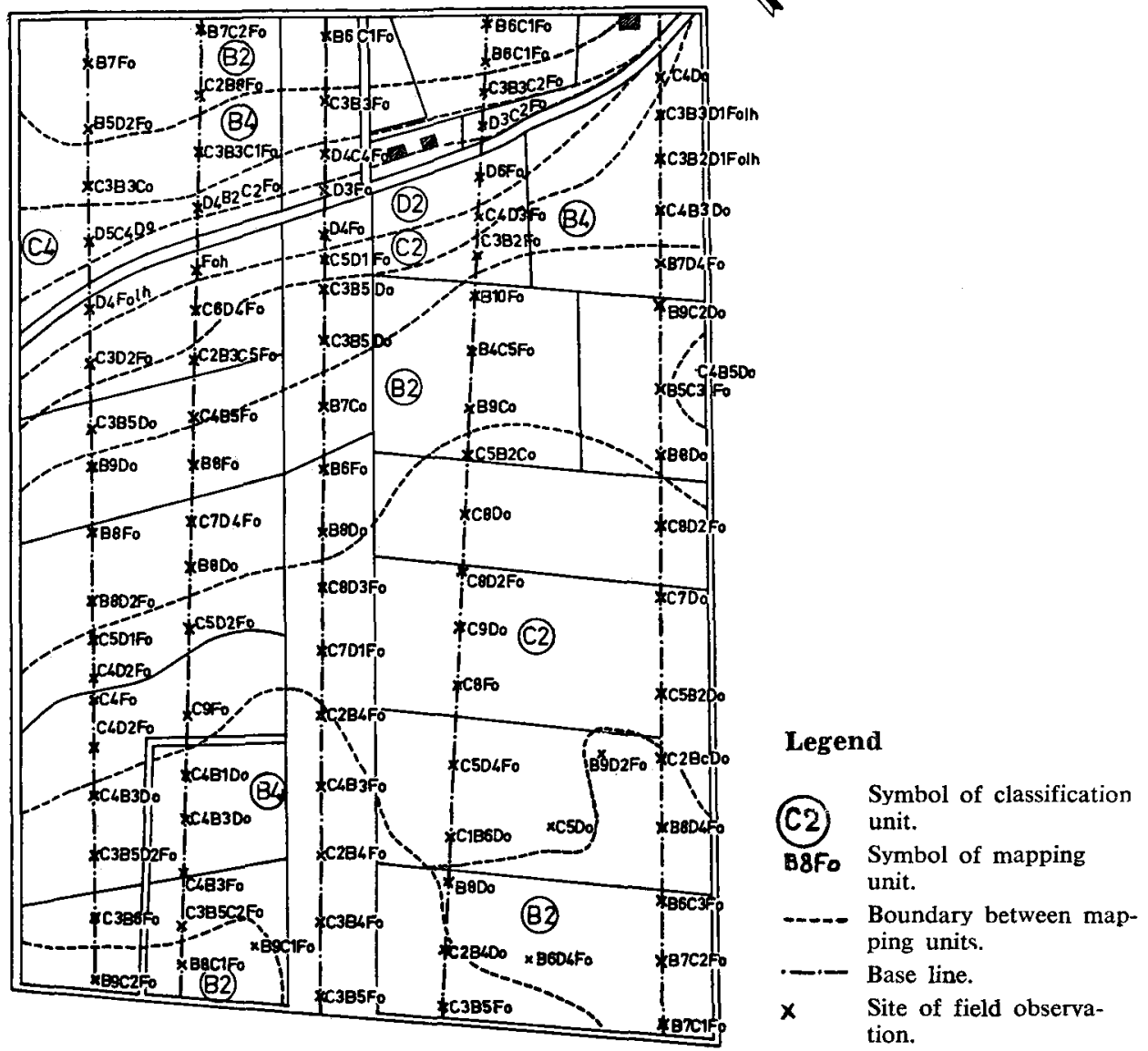


field the most suitable points of observation. A map indicating the location of the points of observation (FIG. 7) does not show a grid or rectangular pattern. This mapping procedure is called "free survey" (STEUR, 1961). This kind of survey is especially important for less detailed soil maps. The mapping units then have to be choosen in such a way that their boundaries are easily observable in the terrain.

Sometimes the original field data have to be studied again afterwards. If the soil mapping is carried out according to a grid or rectangular system, data on the regularly distributed observations are available. In applying the procedure of "free surveying", however, less profiles are studied and the location of a great percentage of these observations does not represent the soil conditions, because many of them were made in transitional zones between different soil units (STEUR, 1961).

Experienced surveyors plot soil boundaries in the field. Taking into account the number of observations (4 to 9) per sq. $\mathrm{cm}$ of the soil map, only little space is available between two observation points on the map. Consequently all surveyors will plot a soil boundary on almost the same spot on the map.

FIG. 7. Part of a field map; free survey. After STeUR (1961)

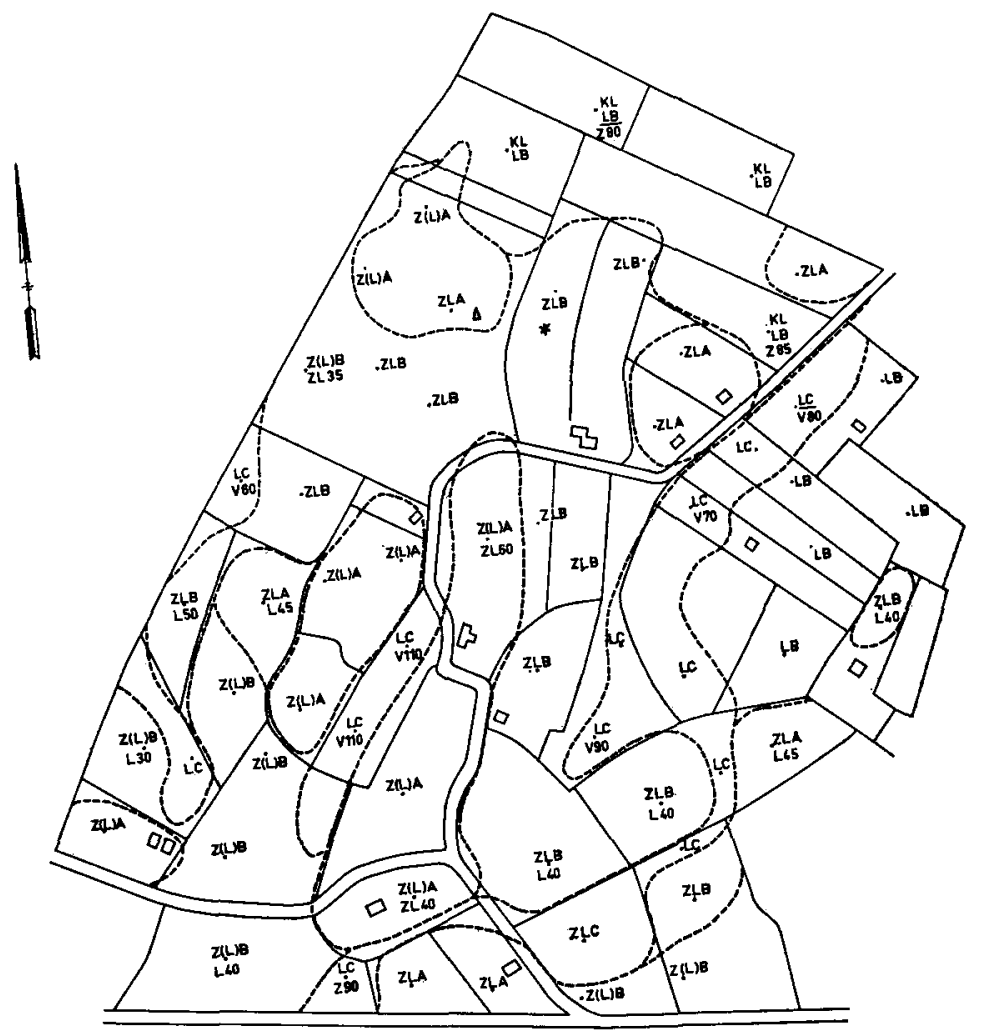

\section{Legend}

zLa Symbol of mapping unit.

---- Boundary between mapping units.

- Site of field observation. 
A difficulty often is how to connect the boundaries which meet or cross. Additional field observations mostly do not give a solution because they are made in transitional zones. Many soil boundaries do not represent sharp and clear lines and often are plotted in the middle of a transitional zone between two soil units. The pattern of soils, as shown on a soil map, is highly influenced by the manner in which boundaries are connected. This has to be done in a logical way (FIG. 8) to get an intelligible map. For this reason the soil surveyor should understand how soil units are associated.

Many soil maps show wrong boundaries at the border of the surveyed area. This can be avoided by making additional field observations just outside the area.

FIg. 8. Connecting soil boundaries has to be done in a logical way

A. Wrong connections ;

B. Correct connections.

Creek-ridge pattern in a sea-clay inversion landscape.

A

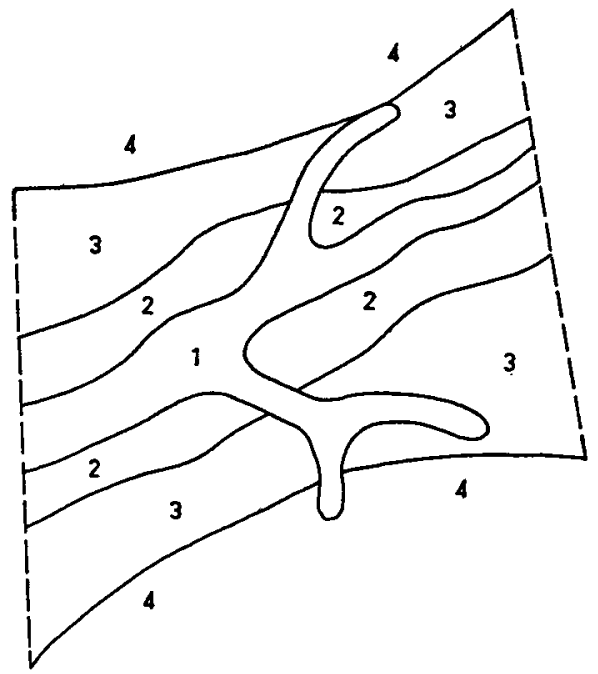

B

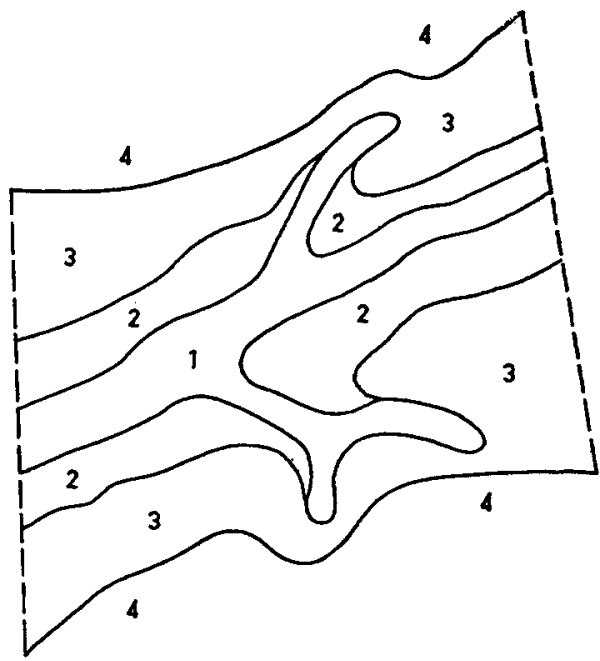

\section{Legend}

1. Calcareous sandy loam.

2. Slightly calcareous loam, overlying non-calcareous clay between 60 and $100 \mathrm{~cm}$.

3. Non-calcareous clay loam, overlying non-calcareous clay between 40 and $60 \mathrm{~cm}$.

4. Non-calcareous clay.

\section{Types of soil maps}

In the course of time various types of soil maps have been published. Very often the type of soil map is indicated by the scale of the final (printed) map. As there is no general agreement on the scale of maps to be published, confusion exists in particular on the names indicating the type of soil map. Preference, therefore, should be given to a map name indicating the presentation of the kind of soil units shown on the map. 
It is proposed to get at least some uniformity. Therefore, it is necessary to agree on the following points :

1. The soil survey report should give a detailed description of:

a. the soil mapping units, properties and qualities and also the characteristics on which the classification is based,

b. the number of field observations per ha, sq. $\mathrm{km}$ or sq. mile and the method of field mapping which has been used,

c. the surface area of the basic mapping unit,

d. the cartographic uniformity and the uniformity of the soils.

2. Besides the scale, the area of the basic soil unit should be indicated by a small square or rectangular (see FIG. 1, 2 and 5).

In this connection it is tentatively proposed to give the following names to the different types of soil maps:

\begin{tabular}{|c|c|c|c|}
\hline Name of the soil map & $\begin{array}{l}\text { Area of the } \\
\text { basic soil } \\
\text { unit in ha }\end{array}$ & $\begin{array}{l}\text { Average scale } \\
\text { of the final } \\
\text { map }\end{array}$ & $\begin{array}{l}\text { Variations in scale } \\
\text { of the map }\end{array}$ \\
\hline Special soil map & $<0,1$ & $1: 5.000$ & up to $1: 7.500$ \\
\hline Detailed soil map .... & $0,1 \longrightarrow 0,5$ & $1: 10.000$ & $1: 7.500-1: 17.000$ \\
\hline Semi-detailed soil map . & $0,5-3,0$ & $1: 25.000$ & $1: 17.000-1: 35.000$ \\
\hline Reconnaissance soil map & $3,0-15$ & $1: 50.000$ & $1: 35.000-1: 75.000$ \\
\hline General soil map $\ldots$. & $15-60$ & $1: 100.000$ & $\begin{array}{l}1: 75.000 \\
1: 250.000\end{array}$ \\
\hline Schematic soil map & $>60$ & $1: 500.000(?)$ & $\begin{array}{l}\text { smaller than } \\
1: 250.000\end{array}$ \\
\hline
\end{tabular}

3. It is also necessary to indicate the taxonomic soil units occurring in every soil mapping unit.

In particular, it should be clearly indicated whether the mapping units are mainly comparable to taxonomic units or to soil associations. This seems of particular importance for the semi-detailed and the reconnaissance soil maps.

A small-scale soil map almost always shows soil associations, whereas most detailed soil maps on large scales show taxonomic units. A semi-detailed soil map could be given an additional name like "soil series map" or "soil association map". A reconnaissance map could be indicated as a "soil family map" or "soil association map".

From the foregoing it may appear that in soil survey mapping criteria, soil units and number of observations somehow correlate with each other and with the purity of mapping units and the accuracy of soil boundaries.

It will be necessary to study the intercorrelation between these factors and their connection with the soil pattern.

This will enlarge the insight in the problems of soil surveying and will lead to an improvement of our knowledge about soil by means of soil survey. 
BAKKER, G. DE

BurINGH, P.

Edelman, C. H.

Edelman, C. H. e.a.

KONING, J. C. DE, and A. J. WIGgers

LIERE, W. J. VAN

MeER, K. VAN DER

Oosting, W. A. J.

Soil Survey Staff

Soil Survey Staff

Schelling, J.

Smits, H., and

A. J. WIGGERS

SonNeveld, F.

Stephens, C. G.

Steur, G. G. L.

VEENENBos, J. S.

VINK, A. P. A.

ZuUR, A. J.

\section{I T ERAT URE}

1950 De bodemgesteldheid van enkele Zuidbevelandse polders en hun geschiktheid voor de fruitteelt. Thesis, Wageningen. Versl. Landbouwk. Onderz. No. 56.14.

1951 Over de bodemgesteldheid rondom Wageningen. Thesis, Wageningen. Versl. Landbouwk. Onderz. No. 57.4.

1953 Bodemkartering en interpretatie van bodemkaarten. Landb. Voorl. 10, 6: 229--233.

1960 The application of aerial photographs in soil surveys, in: Manual of Photographic Interpretation, Washington, 633-666.

1945 De bodemkartering in Nederland. Cultivator. Re-issued in : Boor en Spade. No. I (1948) 78-113.

1950 Soils of the Netherlands. Amsterdam.

1950 Een bodemkartering van de Bommelerwaard boven den Meidijk. Versl. Landbouwk. Onderz. No. 56.18.

1955 Over de bodemgesteldheid van Oostelijk Flevoland. Van Zee tot Land. No. 15. Zwolle.

1948 De bodemgesteldheid van het Westland. Thesis, Wageningen. Versl. Landbouwk. Onderz. No. 54.6.

1949 Bodemkartering, in: Bodemkundige Voordrachten. Landbouw. 9, 44-54.

1940 Een en ander over practische veldbodemkunde. Landbouwk. Tijdschr. 52, 731-747.

1951 Soil survey manual. Washington.

1960 Soil classification, a comprehensive system, 7th approximation, U.S. Dept. Agriculture.

1959 Doel en principe van de moderne bodemclassificatie. Landbouwk. Tijdschr. 71, 737-743.

1959 Soil survey and land reclamation as applied to reclamation of sea bottom land in the Netherlands, Wageningen. Intern. Inst. Land Reclamation and Improvement. Publ. No. 4.

1958 Bodemkartering en de daarop afgestemde landbouwkundige onderzoekingen in het Land van Heusden en Altena. Thesis, Wageningen. Versl. Landbouwk. Onderz. No. 64.4.

1953 Soil surveys for land development. F.A.O. Agr. Series No. 20. Rome.

1959 Aard en opzet van het Nederlandse systeem van bodemclassificatie. Landbouwk. Tijdschr. 71, 744-753.

1961 Methods of soil surveying in use at the Netherlands Soil Survey Institute. Boor en Spade. No. XI, 59-77.

1950 De bodemgesteldheid van het gebied tussen Lemmer en Blokzijl in het randgebied van de Noordoostpolder. Thesis, Wageningen. Versl. Landbouwk. Onderz. No. 55.12.

1949 Bijdrage tot de kennis van löss en dekzanden. Thesis, Wageningen.

1961 Survey problems and air photo interpretation in soil surveys. Stencil I.T.C., Delft.

1951 Ontstaan en aard van de Noordoostpolder. Van Zee tot Land. No. 1, Zwolle. 